\title{
THE IMPORTANCE OF NEW MATERIALS DEVELOPMENT FOR INCREASING GAS TURBINES EFFICIENCY
}

\author{
F. A. Souza ${ }^{\mathrm{a}}$, \\ F. M. Bastos ${ }^{\mathrm{b}}$, \\ and P. R. M. Jorge ${ }^{\mathrm{c}}$ \\ EMBRAER \\ PEE - Programa de Especialização em \\ Engenharia \\ Rodovia Pres. Dutra, Km 134 \\ Caixa Postal 8010 Eugênio de Melo \\ Posto de correio $515 \mathrm{DPE}$ \\ 12247-820, São José dos Campos, SP - Brasil \\ afabio.alexandre@embraer.com.br \\ bfausto.bastos@embraer.com.br \\ cpaulo.jorge@embraer.com.br
}

\author{
ABSTRACT \\ This study shows the effects of new materials for gas turbines and techniques for blade \\ coating. The implication on temperature limits of combustion chambers and consequently \\ on high efficiency is also analyzed. \\ Keywords: turbine, temperature, materials, super alloys, coatings.
}

\section{INTRODUCTION}

The first successful flights of jet enginepowered airplanes (in World War II, by the German and British military) were made with materialslimited engines of relatively modest performance. As they advanced, jet engines continued to be materials oriented. Nonetheless, a look at the material progress since 1942 shows a spectacular series of developments that permitted uninterrupted increases in temperature and operating stress. The developments were both process- and alloyoriented, and often a combination of the two. As a result, the net $3600 \mathrm{~N}$ thrust of the 1942 engine has risen to the level of $380,000+\mathrm{N}$ of today's engines like the GE 90 - a factor over to 100 in little more than 50 years.

Super alloys development respond to the need for materials with creep and fatigue resistance at high temperatures. Historically, these needs have been most acute in aircraft jet engines and other gas turbines, although applications exist in heat exchangers and high-performance heat engines operating with other thermodynamic cycles.

In the history of the development of gas turbines, when goals were either high efficiency or high work output for a given size device, the designers moved to higher operating temperatures. This is the fundamental reason for the development and application of super alloys and thermal barrier coatings and their continued improvement.

\section{COST EFFECTS OF IMPROVING TURBINE INLET TEMPERATURE}

Super alloy applications continue to increase in spite of their high cost. This is due to the considerable economic advantage that results from the relatively small region of an aircraft or powerplant that is exposed to the highest temperatures for the thermodynamic cycle. In a modern aircraft engine or gas turbine, for example, about $0.04 \mathrm{~kg}$ of super alloy is used in the combustion and turbine section per kilowatt of power produced. As can be seen from Fig. 1, if the turbine inlet temperature could be increased $56 \mathrm{~K}\left(56^{\circ} \mathrm{C}\right)$, power output could be increased $4 \%$. If a gas turbine is sold for $\$ 100 / \mathrm{kW}$, an up rate of $56 \mathrm{~K}$ could result in increased revenue to the manufacturer of $\$ 4 / \mathrm{kW}$ of the original rating. If the $56 \mathrm{~K}$ increase in turbine inlet temperature was due solely to the improvement in the hot-section material, the break-even added alloy cost would be about $\$ 20 / \mathrm{kg}$.

A similar example of alloy advantage can be drawn from a case involving a combined BraytonRankine cycle powerplant. About $2 \%$ of the cost of the turbines in such a powerplant is due to the super alloys used. From a recent study of electric power generation, one finds that the levelized average carrying charge (reflecting the cost of the plant) is on the order of $7.5 \mathrm{mils} / \mathrm{kWh}$ ). A fuel cost of $75 \mathrm{mils} / \mathrm{kWh}$ is reasonable. Figure 2 shows that efficiency could be increased $2.25 \%$ by increasing turbine inlet temperature 


\section{TECNOLOGIA/TECHNOLOGY}

$56^{\circ} \mathrm{C}$. At these fuel and plant costs, a break-even situation would exist if a plant cost increase of $22.5 \%$ permitted this temperature increase. If only hot-section material changes were required, the alloy cost for the hot-section material could be increased 11 times.

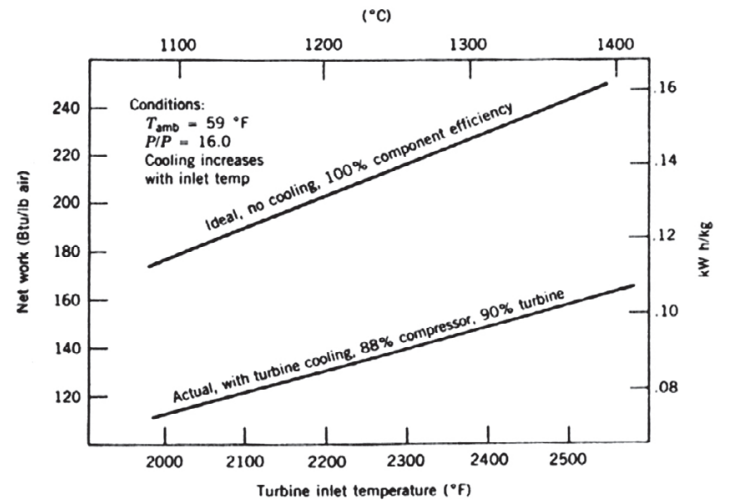

Figure 1. Simple Cycle Net Work (Hagel, 1987).

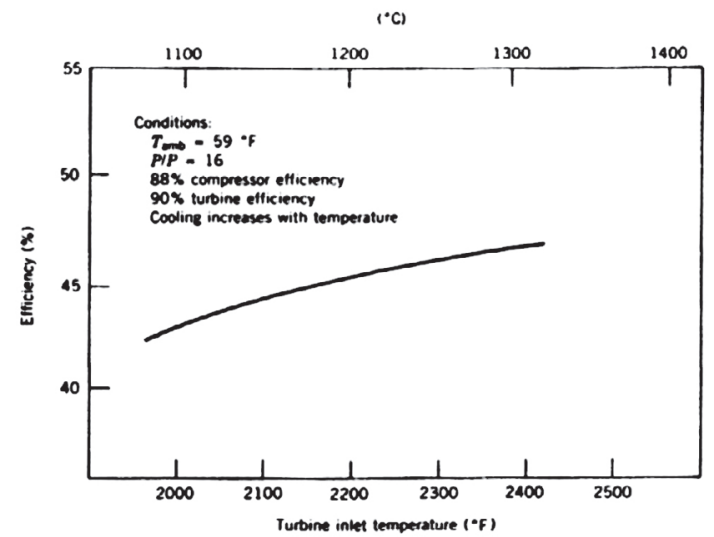

Figure 2. Brayton-Rankine cycle efficiency (Hagel, 1987).

\section{Statistical Representation of Material Behavior}

It is to the mutual benefit of the turbine manufacturer and user to be able to accurately predict the life of hot-section components. Failures that require the shutting down of the turbine are second in significance only to those resulting in the escape of failed components or fragments from the engine. Among such failures are blade creep and fatigue failures where in a significant portion of the blade comes adrift in the gas path, in turn causing the failure of other gas path components. The prediction of such failures is the prediction of the failure of the weakest blade in a stage.

An acceptable failure density in the turbine's life is typically less than 5\%; values like $1 \%$ are more appropriate. Figure 3 shows the histogram for material failure superimposed on that for turbine failure for a machine containing 300

\section{F. A. Souza et al. The Importance of New Materials...}

blades. For the purpose of this example, variables in operating environments are not considered. They would widen the shape of the bell curves. In this example, the $1 \%$ machine failure density point is separated from the average material failure point by about four standard deviations. What this means to the turbine bucket designer is that material data are required that allow the life calculation of this worst blade in 100 turbines ( 30000 blades).

A quick look at where we have been is good preparation for contemplating the future. Considering only stress rupture strength versus time, Fig. 4 depicts progress versus time for the forged and cast super alloys used as turbine blades and vanes. Between 1940 and 1970, temperature capabilities of the alloys shown grew at about $10^{\circ} \mathrm{C} /$ yr, until an upper asymptote was reached for conventionally cast polycrystalline super alloys. Figure 4 shows that since the early 1960s two families of blade and vane materials have been available. The alloys in the upper band offer maximized stress rupture strength and generally poor hot-corrosion resistance while those in the lower band offer relatively good hot corrosion at lower strength levels. The two families evolved as increasingly higher alloy contents forced a choice between high strength and metallurgical stability at low (8-12\%) chromium levels or good corrosion resistance and stability at higher (14-16\%) chromium levels.

Figure 5 presents another way of looking at the data from Fig. 4 and developments of recent years. Three eras become apparent: the weak alloys producible by air melting in the early years, the stronger alloys plateauing about 1970 made by vacuum melting, and the current era of highstrength alloys having directional anisotropic macrostructures and properties.

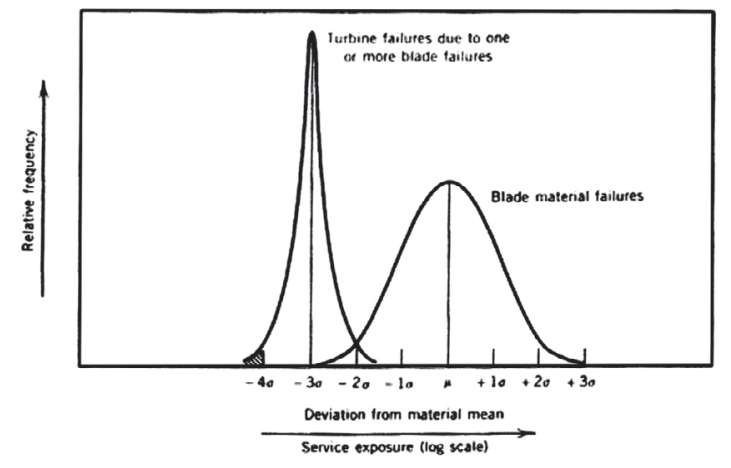

Figure 3. Comparison of material and turbine failure distributions for hypothetical 300-blade turbine (Hagel, 1987). 


\section{TECNOLOGIA/TECHNOLOGY}

\section{Thermal Barrier Coatings}

Thermal barrier coatings (TBCs) are now used on hot section components in most commercial turbine engines. They are used to enhance the temperature differential between the gas and the underlying metal surfaces. They comprise several layers designed to simultaneously provide thermal and oxidation protection. They have microstructures that afford sufficient strain tolerance they remain attached despite severe thermomechanical cycling. Eventually, they spall. This happens because a thin, highly stressed, thermally grown oxide (TGO) develops beneath the TBC.

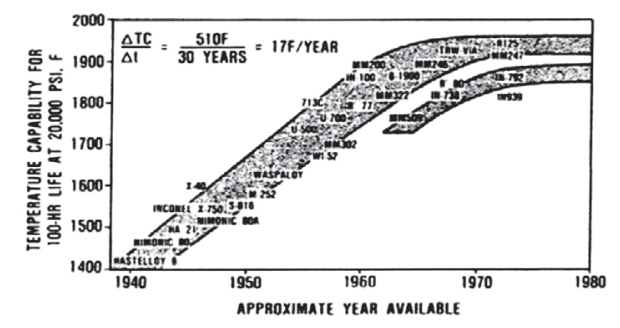

Figure 4. Temperature capabilities of super alloys (Hagel, 1987).

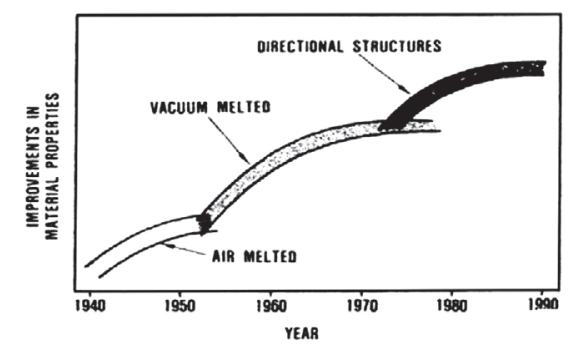

Figure 5. The three eras of super alloys processing (Hagel, 1987).

\section{The Thermal Barrier System}

Thermal barrier coatings (TBCs) comprise thermally insulating materials having sufficient thickness and durability that can sustain an appreciable temperature difference (up to $100^{\circ} \mathrm{C}$ ) between the load bearing alloy and the coating surface. The benefits of these coatings result from their ability to sustain high thermal gradients in the presence of adequate backside cooling.

Lowering the temperature of the metal substrate surface prolongs the life of the component, whether from environmental attack, creep rupture, or fatigue. In addition, the coating reduces the thermal gradients in the metal substrate, reducing the driving force for thermal fatigue. Both of these benefits can be traded off in design for either greater component durability, or for reduced

\section{F. A. Souza et al. The Importance of New Materials...}

cooling air or higher gas temperature and improved system efficiency. As a result, these coatings have been increasingly used in turbine engines.

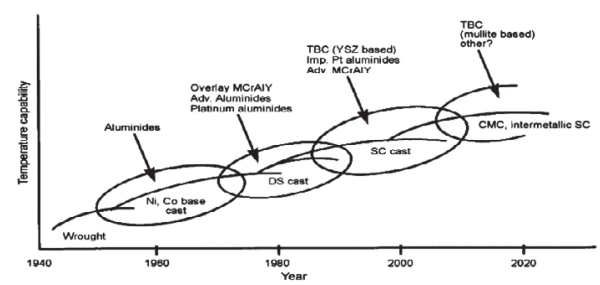

Figure 6. Used coatings since 1940 (Engine Yearbook, 2001).

Successful implementation has been realized using comprehensive testing protocols to specify performance domains, facilitated by engineering models. Expanded application to more demanding scenarios requires that their basic thermomechanical characteristics be understood and quantified, including the associated failure mechanisms.

\section{Benefits}

Major benefits that result from thermal barrier coatings are as follows:

- Save energy through extending the life of coated components, such as first-stage high pressure turbine blades and other hot section components of gas turbines;

- Potential to save approximately $\$ 290,000$ per year per turbine due to extended coating wear life;

- Early results show the new coating has the potential to outperform two-layer MCrAlY aluminide coatings by 60 to 100 percent;

- Preserves high-temperature oxidation protection of MCrAlY coatings;

- Eliminates the regulated chemical waste generated by current processes.

\section{CRITERIA FOR MATERIAL SELECTION}

For the material selection, the key points are the first stages turbine disks and blades where the stresses and temperatures are the highest. The first criteria being high temperature tensile strength and stress to rupture, other properties as resistance to thermal fatigue must be considered in design. Notch sensitivity is also probably detrimental to the high cycle fatigue of rotating parts of 


\section{TECNOLOGIA/TECHNOLOGY}

complicated shapes. Possible corrosion effects of environment should also be considered for the materials' choice as helium impurities can influence the metallic material properties in service via carburization and oxidation mechanisms.

However, for the complete assessment of structural integrity, the combined effect of different failure modes must be considered and particularly the following:

- Creep-fatigue: it is generally considered that the amount of fatigue endurance reduction by creep or relaxation is increased when the material has low creep strength. Creep ductility can also be considered as a limiting parameter in creep-fatigue; - Fatigue and environment effect: initiation of cracks particularly in case of thermal fatigue takes place at the surface of the material and can be influenced by the effects of the environment on the material surface;

- Creep-fatigue and environment effect: the effect of environment can be important in creep-fatigue and in thermal fatigue, and experiments have shown that the reduction of fatigue life by hold times in relaxation can be quite different in vacuum from what is observed in air. The corresponding mechanisms are difficult to clarify for a quantitative prediction, the helium effects being suspected to be intermediate between vacuum and air effects.

Based on these requirements, the selection of metallic materials for blades and disks is discussed in the next section.

\section{Materials for Turbine Disks}

Many of the high temperature alloys with Cobalt have the highest mechanical properties and they are examined in the case of further acceptability.

Inconel alloy 718 was selected for turbine disks in recent studies. Alloy IN718 is a nickelbased precipitation hardened material. It has the necessary strength, short term creep and corrosion resistance only in the case of active cooling of the disk. With a turbine inlet temperature of $850^{\circ} \mathrm{C}$, IN718 will require cooling to lower the temperature of the disks to around $650^{\circ} \mathrm{C}$. Alternatively, alloys containing cobalt may be better in terms of high temperature strength.

In the case of large components as the turbine disks, the manufacturing capability is closely related to the strength of the alloy. In the

\section{F. A. Souza et al. The Importance of New Materials...}

case of nickel-base super alloys, the two major issues are the following:

- To obtain large ingots ( 5-10 tons) without solidification porosities and macro-segregations. For recent super alloys, manufacturing route includes a vacuum induction melting, a vacuum arc remelting and/ or electro-slag remelting. The powder metallurgy would allow to produce high quality ingots with highly alloyed grades. In this case, microstructural inhomogeneities would be limited to the size of the powder particles;

- To forge these ingots which usually offer a very low hot-workability. Isothermal forging is used, but with the most recent super alloys (like Udimet 720), the maximum forgeable size is much lower than the disk diameters. Again, elaboration of near-net shapes components by Hot Isostatic Pressing (HIP) of powders appears promising for these large disks, as hipping furnaces with large diameters are available $(\sim 1.4 \mathrm{~m})$.

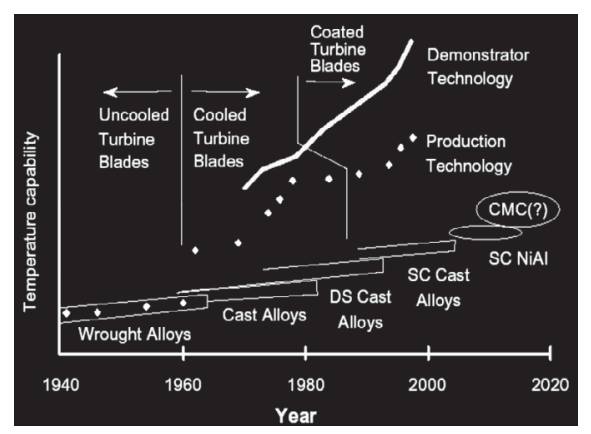

Figure 7. Turbine material progression (Engine Yearbook, 2001).

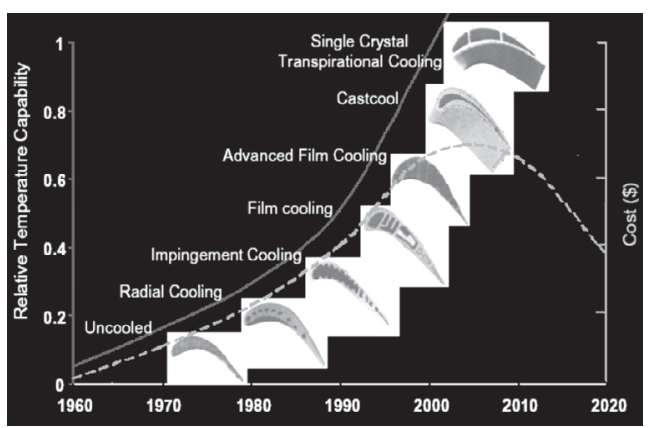

Figure 8. Engineering improvements on turbine blades (Engine Yearbook, 2001).

\section{Materials for Turbine Blades}

Materials selection and testing for turbine blades has been extensively studied. Essentially 3 types of metallic materials were investigated:

- Nickel-base cast super alloys.

- Molybdenum-base grades.

- Niobium alloys 


\section{TECNOLOGIA/TECHNOLOGY}

\section{Ni-Base Cast Super Alloys}

In several past programs, selected alloys were ranked by their high temperature strength, cast ability and cobalt content. Most promising alloys for the blades are therefore:

- 713LC

- M21

- MAR-M 004

- Nimonic 80A with medium creep rupture strength that is envisaged for the last row of blades (lower temperature).

- Alloys Nimonic 90, 105 and 115, Udimet 520 et 700, IN 591, IN738, IN 792, René 80, M22, MARM 247, Nx 188 were also proposed in various applications.

Alloy 713LC is a cast nickel base precipitation hardened alloy that combines superior cast ability and creep resistance. Alloy 713LC has the advantage of wide industrial experience in conventional gas turbine (turbine housings, case, and stators). Alloy 713LC neither contains Co or Ta nor should therefore not present any contamination problems. Alloy 713LC can be susceptible to carburization and sulfidation problems, and coatings have to be envisaged. Alloy 713LC is well suited for the turbine blades required specifications, except for the first row of blades where cooling would be necessary to achieve the required lifetime. Directionally Solidified (DS) or Single Crystal (SC) blades would solve this problem, but alloys commonly used for DS or SC blades contain about 10\% cobalt (DS Mar M 247, SC René N4).

Alloy M21 is a low chromium nickel base alloy that combines precipitation hardening and solid solution hardening ( $~ 10 \%$ tungsten addition). It was selected for its superior corrosion resistance in impure helium. Alloy MM004 has been developed from alloy 713LC and is claimed to have a better toughness because of Hafnium addition.

\section{Molybdenum-Base Alloys}

The molybdenum-base alloy TZM (Mo$0.5 \mathrm{Ti}-0.08 \mathrm{Zr}$ ) has not been used in industrial gas turbines because of its poor oxidation resistance in air. Mo-TZM exhibits a completely different creep-resistance behavior as compared to the nickel-base alloys, mainly because of its high melting point $\left(2607^{\circ} \mathrm{C}\right)$. Almost flat creep curves

\section{F. A. Souza et al. The Importance of New Materials...}

make a $100000 \mathrm{~h}$ life time appear possible with an uncooled blade, as shown in Fig. 3.

Precision forged blades were fabricated; starting from vacuum-arc-melted or powder metallurgy ingots. These blades showed a very high corrosion resistance in impure helium, but several fabrication difficulties and inherent drawbacks were encountered, and efforts for further development are almost abandoned today:

- Mo-TZM is brittle at temperatures up to 360$440^{\circ} \mathrm{C}$ and the notch sensitivity remains high at turbines service temperature.

- In case of air ingress in the circuit, this alloy will suffer a massive oxidation.

- Microstructure is heterogeneous in the blade, as a result of locally non-uniform deformation state during hot forging. Low strength areas were found in fatigue and creep, especially in the airfoil/root transition zone.

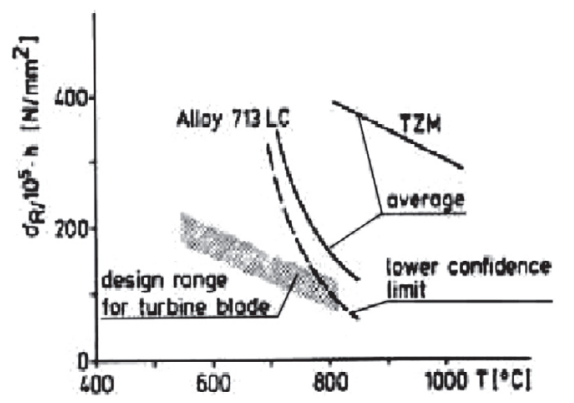

Figure 9. Stress for rupture in $10^{5} \mathrm{~h}$ versus design temperature for turbine blades (Couturier).

\section{Niobium Alloys}

Columbium (niobium- $-\mathrm{Nb}$ ) is vital as an alloying element in superalloys for aircraft turbine engines. Columbium and niobium are synonymous names for the chemical element with atomic number 41; columbium was the first name given, and niobium was the name officially designated by the International Union of Pure and Applied Chemistry in 1950. The metal conducts heat and electricity relatively well, has a high melting point (about 2,470 C), is readily fabricated, and is highly resistant to many chemical environments. Columbium, in the form of ferrocolumbum, is usual worldwide, principally as an additive to improve the strength and corrosion resistance of steel. Because of its refractory nature, appreciable amounts of columbum in the form of high-purity ferrocolumbum and nickel columbum are used in nickel-, cobalt-, and iron-base superalloys for applications such as jet engines components, rocket 


\section{TECNOLOGIA/TECHNOLOGY}

subassemblies, and heat-resisting and combustion equipment.

Most of the niobium oxide production is destined to the industry of superalloys. In 1997, 2,800 tons of niobium oxide had been approximately consumed in the whole world in the production of superalloys. They is esteem that $60 \%$ of the niobium used in the superalloys are directed to the construction of turbines for the industries aeronautical and aerospace, as is observed to follow it:

Table 1. Use of superalloys with $\mathrm{Nb}-1997$.

\begin{tabular}{|l|l|}
\hline Final use & Nb ton \\
\hline Aircraft turbines & 1150 \\
\hline Stationary turbines & 285 \\
\hline Other uses & 465 \\
\hline Total & $1900^{*}$ \\
\hline
\end{tabular}

\section{POTENTIAL BENEFIT OF RECENT ADVANCES IN GAS TURBINE MATERIALS}

\section{Evolutions in Turbine Technology}

There has been a considerable development in natural gas fired advanced land-based turbines with combined cycles (reaching 60\% thermal efficiency). These units are intended for base-load operations, with power continuously increasing: from 60-70 MW in the 70's to $280 \mathrm{MW}$ today and around $500 \mathrm{MW}$ in the next years (GE MS 7001H turbine in 2001). The need to increase engine combustion temperature to increase the efficiency of gas turbines has resulted in a large increase in Turbine Inlet Temperature (TIT), for both land-based and aero turbines. In the last 50 years, the TIT has risen from around $800^{\circ} \mathrm{C}$ to nearly $1600^{\circ} \mathrm{C}$. This increase has been accompanied by several changes in the materials for the hottest parts. Recent advances in material processing and strength capability are now presented.

\section{Advances in Disk Materials}

This increase in TIT has a significant impact on turbine disks technology. Turbine disks temperatures have risen to $680^{\circ} \mathrm{C}$ and will exceed $700^{\circ} \mathrm{C}$ in future aero-engines. In the past, Waspalloy has been used extensively, and Alloy 718 and Udimet 720 are now replacing it. However, even U720 approaches its limits. Therefore, major efforts are made to produce disks with temperature

\section{F. A. Souza et al. The Importance of New Materials...}

capabilities above $700^{\circ} \mathrm{C}$. Alloy 718 has a large propensity for segregation during casting. For aeroengines, melting technology advances have allowed to produce the required disk diameters of largest engines. However, for power generation, turbine disks can be typically 1.5 meters or more in diameter. Such large components require the production of around 10 tons ingots with subsequent forging. This has not been possible with 718 alloy because of low cast ability, and a new grade with less Mo and Nb was developed (IN 706). This grade allows the production of large disks with modest diminution in mechanical properties. However, melting technology of large 706 ingots remains complex, and the alloy reaches today the limits of its performance. Again, large efforts are put to produce large disks in more resistant 718 grade, and also Udimet 720 for the future.

Large segregation during solidification of highly alloyed grades has forced to move to powder metallurgy processing for which segregation is not an issue. Alloys such as Merl 76 (Pratt\&Whittney), René 88DT (General Electric) and N18 (Snecma) represent the current state of the art for aero-engines.

In the past, hipped powder compacts yielded excellent static properties, however low-life fatigue failure occurred in service. These failures were initiated at defects on powder particle boundaries due to powder contamination. To overcome these problems, atomization and handling of the powders were improved, and post-HIP isothermal forging used to mitigate the influence of contamination. Today, powder metallurgy offers two interesting perspectives: - Production of Ni-base super alloy grades that are almost not cast able (due to excessive segregation) and alloys with a low forgeability.

- Production of net shape parts with minimum final machining.

\section{Advances in Blade Materials}

The rise in TIT has been met by replacing the forged blades by cast blades $\left(\mathrm{T}^{100000 \mathrm{~h}}{ }_{140 \mathrm{Mpa}=} 850^{\circ} \mathrm{C}\right.$ and $\sigma^{850 \mathrm{C}}{ }_{100000 \mathrm{~h}}=175 \mathrm{MPa}$ for IN 738) and the subsequent introduction of directionally solidified (DS) and single crystal (SC) blades $\left(\mathrm{T}^{100000 \mathrm{~h}}{ }_{140 \mathrm{MPa}=} 870^{\circ} \mathrm{C}\right)$ Today peak metal temperatures of over $1100^{\circ} \mathrm{C}$ are experienced in some turbine parts, with service lives around 10 000 hours achievable. The DS process allows blades to operate at temperatures about $25 \mathrm{~K}$ higher than conventional blades. An additional temperature 


\section{TECNOLOGIA/TECHNOLOGY}

increase of about $25 \mathrm{~K}$ is achieved by using blades made of single crystal materials (no grain boundaries). Thermal barriers coatings are extensively used in aircraft turbines, allowing another temperature increase of about $100 \mathrm{~K}$.

\section{CONCLUSIONS}

Future developments in materials will be associated with new turbine designs. Multistructure disks, optimized for low cycle fatigue in the bore and creep resistance in the rim, are today under development. This process route is likely to be more expensive, but it offers the designer to optimize independently the properties of the bore and the rim. This will result in better performance and disk endurance.

Nowadays we can get temperatures of about $1800 \mathrm{~K}$ on combustion chambers. And its necessary cooling for the blades of high pressure turbines. This is made through air bled from the compressors. This cooling is necessary to keep the materials in safe work levels.

It is interesting to have higher temperature on combustion chamber exit and less air bled, because with more air bled from the compressors, we can get less thrust available. Those parameters interfere on turbine performance. So, it is necessary investments in research and development of materials and new manufacturing technologies.

Materials selection for aggressive environments inevitably demands specific solutions, and the "best" material for a given application will be that which offers the most favorable combination of the required properties: mechanical, physical, chemical and/or electrical. Unfortunately, the properties are often inversely related. Metals, for example, give up ductility and conductivity when they are alloyed, deformed or heat-treated to increase strength. Similar relationships hold in ceramic systems. There is no free lunch. One solution to the properties evolved with the recognition that a structure's required bulk properties are often quite different from properties demanded of its surface, and by applying appropriate surface coatings, properties could be placed specifically where they are needed. Out of this concept grew the technology of surface modification. Other than paints, varnishes, lubricants and the occasional weld overlay, the concept of modifying surface properties to enhance serviceability was virtually unknown prior to the 20th Century, and

\section{F. A. Souza et al. The Importance of New Materials...}

it continues to develop in step with the increasingly stringent demands placed on engineering materials. Nowhere is that more apparent than in the aircraft, aerospace and turbine engine industries.

\section{ACKNOWLEDGEMENTS}

This compilation work resulted from discussions during the EMBRAER PEE course on gas turbine performance, which led the authors to find out more about gas turbine materials, a prerequisite for further performance improvements besides new proposed variable-cycle gas turbines. Thanks may be directed to Prof. J. R. Barbosa (ITA), which encouraged the authors to search the web and dive into the library to get acquainted with materials, a subject that normally is outside a performance course scope.

\section{REFERENCES}

Couturier, R., Escaravage, C., High temperature alloys for the HTGR Gas Turbine: Required properties and development needs, pp. 3-5, 9-13.

Datko, J., Eklund, D., Lickfold, R. Scheugenpflug, R., 2001, Aerospace America, December 2001.

Dambra, C., Dorfman, M., 2001, Thermal Barrier Coatings: Improving Thermal Protection, Sulzer Metco Technical Review 4/2001.

Energy Efficiency and Renewable Energy, U.S. Department of Energy.

Hagel, W. C., Sims, C. T., Stoloff, N. S., 1987, Superalloys II; John Wiley \& Sons; p. 27, 28, 31, 32, 54-56, 551, 552.

Haley, P. H, The Gas Turbine of the Future, Rolls Royce Corporation Indianapolis Indiana.

Hoffman, P., Layne, A. W., 1999, Gas Turbine Systems for the 21 st Century, IGTI TurboExpo Indianapolis.

ISD Bulletin February 2001.

Mineração e Metalurgia nº32 - Abril/2000.

Princeton Materials Institute, February 1999, PMI-99-11, Mechanisms governing the performance of thermal barrier coatings.

The Engine Yearbook 2001/2002, Developments in thermal spray coatings/21st century engine technology - Rolls Royce.

VTT Manufacturing Technology: Condition and Life of Gas turbine materials. 